\title{
Correlações genéticas entre escores visuais e características de carcaça medidas por ultrassom em bovinos de corte
}

\begin{abstract}
Marcos Jun Iti Yokoo(1), Juliana Nunes Werneck(1), Márcio Cinachi Pereira(1), Lucia Galvão de Albuquerque(1), William Koury Filho(2), Roberto Daniel Sainz ${ }^{(3)}$, Raysildo Barbosa Lobo ${ }^{(4)}$ e Fabiano Rodrigues da Cunha Araujo ${ }^{(5)}$

(1)Universidade Estadual Paulista, Faculdade de Ciências Agrárias e Veterinárias, Departamento de Zootecnia, Via de acesso Prof. Paulo Donato Castellane, s/no, CEP 14884-900 Jaboticabal, SP. E-mail: yokoomarcos@hotmail.com, cewerneck@yahoo.com.br, marciocinachi@yahoo.com.br, Igalb@fcav.unesp.br (2)Brasilcomz, Zootecnia Tropical, Rua Prof. Marcos Antônio Giannoni, no 167, Casa 109, CEP 14882-225 Jaboticabal, SP. E-mail: william@brasilcomz.com ${ }^{(3)}$ University of California, Department of Animal Science, One Shields Avenue, Davis, CA 95616, USA. E-mail: rdsainz@ucdavis.edu (4)Associação Nacional de Criadores e Pesquisadores, Rua João Godoy, № 463, CEP 14020-230 Ribeirão Preto, SP. E-mail: raysildo@ancp.org.br (5)Aval Serviços Tecnológicos, Rua da República, oㅡ28, Sala 102, Bairro Parque das Américas, CEP $38045-170$ Uberaba, MG. E-mail: faraujo@aval-online.com.br
\end{abstract}

\begin{abstract}
Resumo - O objetivo deste trabalho foi estimar correlações genéticas e fenotípicas entre escores visuais e características de carcaça medidas por ultrassom, para verificar a eficácia desses escores na determinação da musculosidade e na avaliação da carcaça. As características de carcaça medidas por ultrassom foram área de olho de lombo (AOL) e espessura de gordura subcutânea (EG), mensuradas entre a região da $12^{a}$ e $13^{a}$ costelas, bem como a espessura de gordura subcutânea na garupa (EGP8). As características de estrutura (E), precocidade (P) e musculosidade (M) foram avaliadas por meio de escores visuais. Os componentes de covariância usados para estimar as correlações genéticas e fenotípicas foram obtidos pelo método da máxima verossimilhança restrita, em uma análise multicaracterística. As estimativas de correlações genéticas entre AOL e E, P e M foram 0,54, 0,58 e 0,61 , respectivamente, e indicaram que, a longo prazo, a utilização da AOL como critério de seleção poderá produzir animais com maiores escores visuais para essas características. As correlações genéticas estimadas entre as espessuras de gordura (EG e EGP8) e os escores P e M apresentaram comportamento semelhante. Entretanto, as correlações genéticas entre as espessuras de gordura (EG e EGP8) e E foram próximas de zero. As correlações fenotípicas seguiram as mesmas tendências das respectivas correlações genéticas. Essas estimativas indicam que os escores visuais são determinados, em parte, pelos mesmos conjuntos de genes que influenciam a AOL.
\end{abstract}

Termos para indexação: componente de variância, correlação fenotípica, herdabilidade, musculosidade, parâmetro genético.

\section{Genetic correlations between visual scores and carcass traits measured by real-time ultrasound in beef cattle}

\begin{abstract}
The aim of this work was to evaluate the genetic and phenotypic correlations between carcass traits measured by real-time ultrasound and by visual scores, in order to verify the effectiveness of these scores in determining muscularity and carcass fat. Carcass traits measured by real-time ultrasound were longissimus muscle area (LMA) and backfat thickness (BF), obtained between the $12^{\text {th }}$ and $13^{\text {th }}$ ribs, as well as the rump fat thickness (RF). The visual scores for the traits of body structure (E), precocity (P), and muscle (M) were evaluated individually. The genetic and phenotypic parameters were estimated by multivariate analysis, using restricted maximum likelihood methodology. The estimated genetic correlations between LMA and $\mathrm{E}, \mathrm{P}$ and $\mathrm{M}$ were $0.54,0.58$ and 0.61 , respectively, indicating that, in the long term, the use of LMA as a selection criterion might produce animals with higher visual scores. Similar genetic correlations were found between both subcutaneous fat measures (BF and RF) and $\mathrm{P}$ and $\mathrm{M}$ scores. However, genetic correlations between both subcutaneous fat measures and $\mathrm{E}$ were close to zero. The phenotypic correlations followed the same trends of their respective genetic correlations. These estimates indicate that the visual scores and LMA are, in part, determined by the same groups of genes.
\end{abstract}

Index terms: variance component, phenotypic correlation, heritability, muscularity, genetic parameter.

\section{Introdução}

Nos últimos anos, o agronegócio brasileiro vem ocupando um espaço importante na produção mundial de alimentos, especialmente no que se refere à carne bovina.
Apecuária de corte brasileira destaca-se pelo grande volume de carne produzida e desempenha papel fundamental na pauta de exportação (Anualpec, 2007). O setor de carnes no Brasil, apesar de ainda não incorporar todas as novas 
tecnologias de produção e gestão, tem evoluído com aumento da produtividade do rebanho e modernização das empresas rurais.

Os organismos governamentais estão instituindo leis que buscam regulamentar os processos produtivos, como o Sistema Brasileiro de Identificação e Certificação de Origem de Carne Bovina e Bubalina (Sisbov). A introdução desse sistema é fundamental para assegurar aos consumidores uma carne de melhor qualidade e garantir a sanidade dos produtos comercializados. Um exemplo disso é o sucesso dos programas de carne certificada, como Nelore Natural, que faz "marketing" relacionado à carne verde, que é o boi produzido exclusivamente a pasto. Esses programas agregam valor comercial à carne certificada, acima do valor do produto como "commodity", e asseguram a padronização da qualidade, requerida pelos diversos mercados consumidores.

Existem várias maneiras de avaliar a qualidade da carcaça com o objetivo de melhorar as características organolépticas da carne. A utilização de métodos de avaliação da qualidade da carcaça que impliquem o abate do animal é desvantajosa, pois os altos custos do teste de progênie limitam o número de animais a serem testados, o que diminui a intensidade de seleção, com consequente decréscimo das respostas à seleção.

A técnica da ultrassonografia permite a avaliação das características da carcaça por um procedimento não invasivo e não deixa resíduos nocivos na carne dos animais. Segundo Fisher (1997), a ultrassonografia passou a ser considerada como técnica para a predição da composição da carcaça de bovinos de corte a partir de 1950 e é considerada uma tecnologia de baixo custo e de fácil aplicação, quando comparada à mensuração realizada diretamente na carcaça após o abate.

Outro método de avaliação de carcaça é a atribuição de escores visualmente, que permitem identificar animais com maior precocidade de terminação, melhor musculatura e conformação frigorífica. Diversos autores demonstraram que, com esse método, grande número de animais pode ser avaliado sem que se precise submetê-los a mensurações, o que minimiza o estresse dos animais, e torna o processo mais ágil e de baixo custo (Jorge Júnior et al., 2001, 2004; Koury Filho et al., 2006; Faria et al., 2008). Apesar de estudos a respeito da estimação dos coeficientes de herdabilidade mostrarem que as características de escores visuais medidas por diversos sistemas são herdáveis (Melis et al., 2003; Koury Filho et al., 2006; Forni et al., 2007; Faria et al., 2008), são poucos os trabalhos que associam as características de escores visuais com quantidade de carne e com a terminação da carcaça (Albuquerque \& Oliveira, 2002).

O objetivo deste trabalho foi estimar as correlações genéticas e fenotípicas entre características de carcaça medidas por ultrassom e por escores visuais, para verificação da eficácia desses escores na determinação da musculosidade e na avaliação da carcaça.

\section{Material e Métodos}

O trabalho foi desenvolvido com dados do Programa de Melhoramento Genético da Raça Nelore da Associação Nacional de Criadores e Pesquisadores. As características foram medidas em dez fazendas, sendo que as mensurações de ultrassonografia em tempo real foram realizadas em 2.590 animais, machos e fêmeas, entre os anos de 2002 e 2004 . Foram coletadas imagens de ultrassom da área de olho de lombo (AOL)e da espessura de gordura subcutânea (EG), mensuradas entre a região da $12^{\mathrm{a}}$ e $13^{\mathrm{a}}$ costelas, transversalmente ao músculo longissimus dorsi. Além disso, foram coletadas imagens da espessura de gordura subcutânea na garupa (EGP8), medida na intersecção dos músculos gluteus medius e biceps femoris, localizados entre o íleo e o ísquio. O aparelho utilizado para realizar as imagens foi um ALOKA $500 \mathrm{~V}$, com sonda linear de $17,2 \mathrm{~cm}$, de 3,5 MHz e um acoplador acústico com um sistema de captura de imagens (Blackbox, Biotronics Inc., Ames, IA, EUA). As imagens foram interpretadas pelo laboratório responsável pela garantia da qualidade dos dados (Aval Serviços Tecnológicos S/C), usando o "Biosoft Toolbox software" (Biotronics Inc., Ames, IA, EUA), que é um programa com precisão de duas casas decimais. Para a coleta das imagens da AOL e EG, foi utilizado óleo vegetal e um acoplante ("standoff"), para garantir o contato acústico entre a sonda linear e o corpo do animal.

As avaliações por escores visuais foram realizadas em seis das dez fazendas. Primeiramente foi observado todo o lote de manejo, o qual caracterizava um grupo de contemporâneos (GC). Dessa forma visualizou-se o perfil médio do GC para cada característica avaliada, que serviu como base de comparação, e as notas de escores visuais foram relativas à cada GC. Posteriormente, os animais foram pesados e avaliados individualmente, 
por um único técnico treinado que atribuiu escores de 1 a 6 , sendo 6 a maior expressão da característica e 1 a menor expressão da característica.

Segundo Koury Filho et al. (2006), as características de escores visuais avaliadas podem ser descritas como: estrutura corporal (E), que prediz a área que o animal abrange vista de lado, considerando basicamente o comprimento corporal e a profundidade de costelas; precocidade $(\mathrm{P})$, que relaciona a profundidade de costelas com a altura dos membros, e corresponde a indivíduos que irão depositar gordura de acabamento mais precocemente, com expectativa de que sejam aqueles com maiores costelas em relação à altura de seus membros; musculosidade (M), que é avaliada pela evidência da massa muscular, sendo que os indivíduos com musculatura mais convexa recebem notas mais altas.

A consistência dos dados foi avaliada para cada uma das características analisadas, usando-se o SAS (SAS Institute, 2000). Em cada GC foram eliminados os animais com medidas fora do intervalo da média \pm três desvios-padrão. Foram excluídos os GC que continham apenas animais filhos de um mesmo touro, os GC sem variabilidade fenotípica e os GC com menos de três animais.

Na formação dos GC, foram consideradas as variáveis ano de nascimento, estação de nascimento, fazenda, sexo e lote de manejo do nascimento à mensuração. Na Tabela 1 está apresentada a constituição do arquivo de dados analisado para as características AOL, EG, EGP8, E, P e M.

Os componentes de covariância foram estimados pelo método da máxima verossimilhança restrita, em uma análise multicaracterística, com uso do modelo animal. Foi utilizado o programa REMLF90 (Misztal, 2002), que emprega o algoritmo de maximização da esperança, com processo de aceleração da convergência. Admitiu- se que a convergência era atingida quando o quadrado das diferenças relativas entre estimativas consecutivas era menor que $10^{-10}$. A matriz de parentesco foi até a última geração conhecida e totalizou 69.872 animais.

O modelo, para todas as características, incluiu o efeito aleatório genético direto, o efeito fixo do GC e a idade do animal como covariável - efeitos linear e quadrático. Os animais medidos tinham de 430 a 620 dias de idade. Para EG e EGP8, o modelo foi o mesmo; apenas acrescentou-se o efeito fixo da idade da vaca ao parto, em classes $(\leq 35 ; 36$ a $47 ; 48$ a $59 ; 60$ a $71 ; 72$ a 119 e $>120$ meses). O modelo completo pode ser representado em notação matricial como: $\mathrm{y}=\mathrm{X} \beta+\mathrm{Za}+\mathrm{e}$, em que y é o vetor das observações; $\beta$ é o vetor dos efeitos fixos e covariáveis; a é o vetor dos efeitos aleatórios que representam os valores genéticos aditivos diretos de cada animal; e é o vetor de efeitos aleatórios residuais; e X e Z são as matrizes de incidência, que relacionam as observações aos efeitos fixos e aos efeitos aleatórios genéticos aditivos diretos, respectivamente. Assumiu-se que $\mathrm{E}[\mathrm{y}]=\mathrm{X} \beta ; \operatorname{Var}(\mathbf{a})=\mathrm{A} \otimes \Sigma_{\mathrm{a}}$ e $\operatorname{Var}(\mathbf{e})=\mathrm{I}_{\mathrm{N}} \otimes \Sigma_{\mathrm{e}}$, em que $\Sigma_{\mathrm{a}}$ é a matriz de covariâncias genéticas aditivas diretas entre as características; $\Sigma_{\mathrm{e}}$ é a matriz de covariâncias residuais; A é a matriz de parentesco; I é a matriz identidade; $\mathrm{N}$ é o número de animais; $\mathrm{e} \otimes$ é o produto direto entre matrizes.

\section{Resultados e Discussão}

$\mathrm{Na}$ Tabela 2 estão apresentadas as estimativas de herdabilidade e de correlações genéticas e fenotípicas das características analisadas. Os valores das estimativas de herdabilidade da AOL, EG e EGP8 foram de moderados a altos, e variaram de 0,37 a 0,55 . Isto indica que a utilização dessas características como critério de seleção, em programas de melhoramento, pode promover progresso genético rápido.

Tabela 1. Descrição do arquivo de dados das características área de olho de lombo (AOL), espessura de gordura subcutânea (EG), espessura de gordura subcutânea na garupa (EGP8), estrutura (E), precocidade (P) e musculosidade (M), da raça Nelore.

\begin{tabular}{|c|c|c|c|c|c|}
\hline Característica & $\begin{array}{c}\text { Número } \\
\text { de animais }\end{array}$ & Média $\pm \mathrm{DP}^{(1)}$ & $\begin{array}{c}\text { Número de touros por } \\
\text { característica }\end{array}$ & $\begin{array}{l}\text { Número de vacas } \\
\text { por característica }\end{array}$ & $\begin{array}{l}\text { Número } \\
\text { de GC }\end{array}$ \\
\hline $\operatorname{AOL}\left(\mathrm{cm}^{2}\right)$ & 2.590 & $48,38 \pm 8,72$ & 244 & 2.451 & 301 \\
\hline $\mathrm{EG}(\mathrm{mm})$ & 2.417 & $1,93 \pm 1,36$ & 231 & 2.302 & 288 \\
\hline EGP8 (mm) & 2.428 & $3,05 \pm 1,97$ & 232 & 2.308 & 291 \\
\hline $\mathrm{E}$ & 1.481 & $3,98 \pm 1,46$ & 132 & 1.460 & 55 \\
\hline $\mathrm{P}$ & 1.481 & $3,85 \pm 1,58$ & 132 & 1.460 & 55 \\
\hline M & 1.481 & $3,81 \pm 1,48$ & 132 & 1.460 & 55 \\
\hline
\end{tabular}

${ }^{(1)}$ As médias e os desvios-padrão da E, P e M foram estimados pelas fórmulas dos valores esperados das variáveis aleatórias multinomiais. ${ }^{(2)}$ Grupos contemporâneos por característica. 
A estimativa de herdabilidade para $\mathrm{AOL}$ foi próxima às obtidas por Johnson et al. (1993), Reverter et al. (2000) e Crews Júnior et al. (2003) nas raças taurinas e compostas $(0,39,0,38$ e 0,37 , respectivamente) e superior às reportadas por Figueiredo et al. (2000) e Yokoo et al. (2008) na raça Nelore ( 0,20 e 0,35 , respectivamente).

A estimativa de herdabilidade da EG foi próxima às descritas por Shepard et al. (1996), Reverter et al. (2000) e Crews Júnior et al. (2003) (0,56, 0,51 e 0,53, respectivamente) e superior às relatadas por Johnson et al. (1993), Robinson et al. (1993), Moser et al. (1998), Crews Júnior \& Kemp (2001), Kemp et al. (2002) e Stelzleni et al. (2002) $(0,11,0,30,0,11,0,46,0,39$ e 0,26, respectivamente) nas raças taurinas e compostas. Na raça Nelore, Figueiredo et al. (2000) e Yokoo et al. (2008) descreveram estimativas inferiores de herdabilidade da EG $(0,04$ e 0,48, respectivamente). As discrepâncias entre os valores encontrados por Figueiredo et al. (2000) e pelos demais autores se deve, provavelmente, à diferença do método de coleta de dados.

A estimativa de herdabilidade da EGP8 foi inferior à encontrada por Reverter et al. (2000) e similar à encontrada por Robinson et al. (1993), ambas em animais taurinos (0,55 e 0,37, respectivamente). Resultados semelhantes em animais Nelore $(0,40)$ foram relatados por Yokoo et al. (2008).

De modo geral, as estimativas de herdabilidade das características de carcaça medidas por ultrassonografia foram superiores na raça Nelore, quando comparadas às estimativas em animais de origem taurina (Reverter et al., 2000; Yokoo et al., 2008). Essa superioridade da proporção da variabilidade genética, em relação à fenotípica, encontrada na raça Nelore, é decorrente, provavelmente, do fato de que animais dessa raça não estão sendo selecionados, para essas características de carcaça, com medidas por ultrassom. As estimativas de herdabilidade obtidas neste trabalho indicam que essas características devem responder rapidamente à seleção individual.
Da mesma forma, os valores das estimativas de herdabilidade da E, P e M variaram de moderados a altos. Estimativas da herdabilidade das características de carcaça, em bovinos Nelore, feitas com o uso do sistema EPM, são limitadas. As estimativas da herdabilidade da $\mathrm{P}$ e $\mathrm{M}$ obtidas neste trabalho são semelhantes às reportadas por Koury Filho et al. (2006): 0,63 $\pm 0,12 \mathrm{e}$ $0,48 \pm 0,11$, respectivamente. Entretanto, a estimativa da herdabilidade da $\mathrm{E}$ foi bastante superior à relatada por esses autores $(0,24 \pm 0,09)$. Lima et al. (1989), ao avaliar a profundidade do tórax por escores visuais, que se assemelha à característica $\mathrm{P}$ do presente trabalho, também relataram valor de herdabilidade alto, de $0,65 \pm 0,22$.

Outros estudos que analisaram escores visuais pelo sistema CPM (conformação, precocidade e musculosidade) relataram estimativas de herdabilidade inferiores às do presente trabalho, com variação de 0,18 a 0,33 (Eler et al., 1996; Melis et al., 2003), na raça Nelore. Faria et al. (2008), ao avaliar características de escores visuais pelo sistema MERCOS (musculosidade, estrutura física, aspectos raciais e sexuais, conformação e ônfalo), também relataram coeficientes de herdabilidade inferiores aos deste estudo, com variação de 0,09 a 0,33, na raça Nelore.

De modo geral, as estimativas de correlações genéticas entre as características de carcaça medidas por ultrassom e as de escore visual foram moderadas e positivas, excetuando-se as encontradas entre $\mathrm{E}$ e as características de espessura de gordura (EG e EGP8), as quais foram baixas e negativas, mas não estatisticamente diferentes de zero $(\mathrm{p}<0,01)$.

As correlações genéticas entre os escores visuais e AOL foram positivas e de magnitude moderada, e indicam que, no longo prazo, a utilização de qualquer escore visual (E, P ou M) como critério de seleção poderá resultar em animais com maior área de olho de lombo. Resultados semelhantes ao do presente trabalho foram

Tabela 2. Estimativas de herdabilidade $\left(\hat{\mathrm{h}}^{2}\right)$, correlações genéticas $\left(\hat{\mathrm{r}}_{\mathrm{g}}\right)$, fenotípicas $\left(\hat{\mathrm{r}}_{\mathrm{f}}\right)$ e residuais $\left(\hat{\mathrm{r}}_{\mathrm{e}}\right)$ das características área de olho de lombo (AOL), espessura de gordura subcutânea (EG), espessura de gordura subcutânea na garupa (EGP8), estrutura $(\mathrm{E})$, precocidade $(\mathrm{P})$ e musculosidade $(\mathrm{M})$, da raça Nelore.

\begin{tabular}{|c|c|c|c|c|c|c|c|c|c|c|}
\hline \multirow[t]{2}{*}{ Característica } & \multicolumn{3}{|c|}{$\operatorname{AOL}\left(\mathrm{cm}^{2}\right)$} & \multicolumn{3}{|c|}{$\mathrm{EG}(\mathrm{mm})$} & \multicolumn{3}{|c|}{ EGP8 (mm) } & \multirow[t]{2}{*}{$\hat{\mathrm{h}}^{2}$} \\
\hline & $\hat{\mathrm{r}}_{\mathrm{g}}$ & $\hat{\mathrm{r}}_{\mathrm{e}}$ & $\hat{\mathrm{r}}_{\mathrm{f}}$ & $\hat{\mathrm{r}}_{\mathrm{g}}$ & $\hat{\mathrm{r}}_{\mathrm{c}}$ & $\hat{\mathrm{r}}_{\mathrm{f}}$ & $\hat{\mathrm{r}}_{\mathrm{g}}$ & $\hat{\mathrm{r}}_{\mathrm{e}}$ & $\hat{\mathrm{r}}_{\mathrm{f}}$ & \\
\hline $\mathrm{E}$ & 0,54 & 0,15 & 0,31 & $-0,02$ & 0,23 & 0,11 & $-0,05$ & 0,19 & 0,09 & 0,42 \\
\hline $\mathrm{P}$ & 0,58 & 0,02 & 0,30 & 0,40 & 0,02 & 0,25 & 0,42 & 0,03 & 0,24 & 0,65 \\
\hline M & 0,61 & 0,16 & 0,35 & 0,38 & 0,10 & 0,24 & 0,41 & 0,09 & 0,24 & 0,49 \\
\hline$\hat{\mathrm{h}}^{2}$ & & 0,37 & & & 0,55 & & & 0,43 & & \\
\hline
\end{tabular}


relatados por Albuquerque \& Oliveira (2002), na raça Nelore. Os autores estimaram correlações de 0,57, 0,56 e 0,63 entre AOL e escores de conformação, precocidade de terminação e musculatura, respectivamente. Estimativas inferiores às deste trabalho foram relatadas por Figueiredo et al. (2000), entre AOL e M $(0,22)$, em machos da raça Nelore, e por Dibiasi (2006), na raça Brangus, que estimou a correlação de Pearson entre as predições das diferenças esperadas na progênie para $\mathrm{Me}$ AOL $(0,32)$.

As estimativas de correlações genéticas entre as espessuras de gordura (EG e EGP8) e os escores visuais $\mathrm{P}$ e $\mathrm{M}$ foram positivas e moderadas, e indicam que essas características são determinadas, em grande parte, por diferentes conjuntos de genes de ação aditiva. Dibiasi (2006) reportou valores semelhantes entre as diferenças esperadas na progênie para EG e P, com variação de 0,37 a 0,63 , em animais de diversas raças. Da mesma forma, Albuquerque \& Oliveira (2002), na raça Nelore, estimaram correlações de 0,38 e 0,37, entre EG e os escores P e M. Entretanto, Figueiredo et al. (2000) afirmaram que as medidas de P não foram precisas em avaliar a deposição de gordura subcutânea, pelo fato de terem observado correlação genética negativa entre EG e P. Diferentemente do encontrado para $\mathrm{P}$ e $\mathrm{M}$, as estimativas de correlação genética entre as espessuras de gordura (EG e EGP8) e E não foram estatisticamente diferentes de zero $(p<0,01)$, e sugerem que a seleção de animais para espessura de gordura não acarretará mudanças na característica estrutura corporal e vice-versa. Resultados semelhantes foram relatados por Albuquerque \& Oliveira (2002), na raça Nelore, que estimaram correlação genética de 0,11 entre EG e escore de conformação. Esses autores concluíram que os escores visuais podem ser usados como critério de seleção para $\mathrm{AOL}$, mas que não são critérios de seleção adequados quando o objetivo é a identificação de animais de terminação precoce.

As estimativas de correlações genéticas entre as características de escores visuais ( $\mathrm{P}$ e $\mathrm{M})$ e as características de carcaça medidas por ultrassom (AOL, EG e EGP8) foram próximas e variaram de 0,38 a 0,61 . Esses resultados podem ser decorrentes da alta correlação genética existente entre $\mathrm{P}$ e $\mathrm{M}(0,86)$, indicativo de que essas características (P e M) são controladas pelos mesmos genes de ação aditiva.

As correlações fenotípicas apresentaram o mesmo comportamento que as correlações genéticas, porém com valores mais baixos, e sugerem que, fenotipicamente, animais com maior AOL, EG e EGP8 não são, necessariamente, os mesmos que apresentam os mais altos valores dos escores visuais. Existem poucos estudos sobre a associação entre as características de carcaça medidas por ultrassom e os escores visuais, o que impossibilita maiores discussões acerca desses resultados.

\section{Conclusões}

1. Os escores visuais e as características de carcaça medidas por ultrassom podem ser incluídos em programas de melhoramento, e devem responder rapidamente à seleção massal.

2. A seleção para escores visuais de precocidade e musculosidade deverá promover mudanças genéticas, no mesmo sentido, na área de olho de lombo, na espessura de gordura subcutânea e na espessura de gordura subcutânea na garupa, medidas por ultrassom.

3. A estrutura, precocidade e musculosidade são determinadas, em grande parte, pelo mesmo conjunto de genes de ação aditiva; a utilização de apenas uma dessas características, como critério de seleção, pode promover mudanças nas demais.

\section{Agradecimentos}

Ao Conselho Nacional de Desenvolvimento Científico e Tecnológico, à Fundação de Amparo à Pesquisa do Estado de São Paulo, à Aval Serviços Tecnológicos $\mathrm{S} / \mathrm{C}$ e à Associação Nacional de Criadores e Pesquisadores de Ribeirão Preto, pelo apoio financeiro; às fazendas Bacuri, Grupo OMB, Grupo Hora, Rancho da Matinha, Colonial, São Dimas, Remanso, Passa Quatro e Santa Marta e aos criadores da raça Nelore que colaboraram para realização deste trabalho.

\section{Referências}

ALBUQUERQUE, L.G.; OLIVEIRA, H.N. Genetic parameter estimates for ultrasound measurements and visual scores in Nelore cattle. In: ANNUAL MEETING OF THE EAAP, 53., 2002, Cairo. Proceedings. Cairo: EAAP, 2002. 1 CD-ROM.

ANUALPEC. Anuário da pecuária brasileira. São Paulo: Instituto FNP, 2007.

CREWS JÚNIOR, D.H.; KEMP, D.J. Genetic parameters for ultrasound and carcass measures of yield and quality among replacement and slaughter beef cattle. Journal of Animal Science, v.79, p.3008-3020, 2001. 
CREWS JÚNIOR, D.H.; POLLAK, E.J.; WEABER, R.L.; QUAAS, R.L.; LIPSEY, R.J. Genetic parameters for carcass traits and their live animal indicators in Simmental cattle. Journal of Animal Science, v.81, p.1427-1433, 2003.

DIBIASI, N.F. Estudo do crescimento, avaliação visual, medidas por ultra-sonografia e precocidade sexual, em touros jovens pertencentes a vinte e uma raças de aptidão para corte. $2006.94 p$. Dissertação (Mestrado) - Universidade Estadual Paulista, Jaboticabal.

ELER, J.P.; FERRAZ, J.B.S.; SILVA, P.R. Parâmetros genéticos para peso, avaliação visual e circunferência escrotal na raça Nelore, estimados por modelo animal. Arquivo Brasileiro de Medicina Veterinária e Zootecnia, v.48, p.203-213, 1996.

FARIA, C.U. de; MAGNABOSCO, C.U.; ALBUQUERQUE, L.G. de; REYES, A. de los; BEZERRA, L.A.F.; LOBO, R.B. Análise genética de escores de avaliação visual de bovinos com modelos bayesianos de limiar e linear. Pesquisa Agropecuária Brasileira, v.43, p.835-841, 2008.

FIGUEIREDO,L.G.G.;ELER, J.P.; FERRAZ, J.B.S.; OLIVEIRA, F.F.; SHIMBO, M.V.; JUBILEU, J.S. Componentes de variância para área de olho de lombo e espessura de gordura subcutânea. In: SIMPÓSIO NACIONAL DE MELHORAMENTO ANIMAL, 3., 2000, Belo Horizonte. Anais. Belo Horizonte: SBMA, 2000. p.385-387.

FISHER, A.V. A review of the technique of estimating the composition of livestock using the velocity of ultrasound. Computers and Electronics in Agriculture, v.17, p.217-231, 1997.

FORNI, S.; FEDERICI, J. de F.; ALBUQUERQUE, L.G. de. Tendências genéticas para escores visuais de conformação, precocidade e musculatura à desmama de bovinos Nelore. Revista Brasileira de Zootecnia, v.36, p.572-577, 2007.

JOHNSON, M.Z.; SCHALLES, R.R.; DIKEMAN, M.E.; GOLDEN, B.L. Genetic parameter estimates of ultrasound-measured longissimus muscle area and $12^{\text {th }}$ rib fat thickness in Brangus cattle. Journal of Animal Science, v.71, p.2623-2630, 1993.

JORGE JÚNIOR, J.; DIAS, L.T.; ALBUQUERQUE, L.G. de. Fatores de correção de escores visuais de conformação, precocidade e musculatura, à desmama, para idade da vaca ao parto, data juliana de nascimento e idade à desmama em bovinos da raça Nelore. Revista Brasileira de Zootecnia, v.33, p.2044-2053, 2004.

JORGE JÚNIOR, J.; PITA, F.V.C.; FRIES, L.A.; ALBUQUERQUE, L.G. de. Influência de alguns fatores de ambiente sobre os escores de conformação, precocidade e musculatura à desmama em um rebanho da raça Nelore. Revista Brasileira de Zootecnia, v.30, p.1697-1703, 2001.

KEMP, D.J.; HERRING, W.O.; KAISER, C.J. Genetic and environmental parameters for steer ultrasound and carcass traits. Journal of Animal Science, v.80, p.1489-1496, 2002.
KOURY FILHO, W.; ALBUQUERQUE, L.G.; ALENCAR, M.M. de; FORNI, S.; CHIQUITELLINETO, M. Genetic parameter estimates of visual score traits and their relationship with growing traits in Brazilian Nelore cattle. In: WORLD CONGRESS ON GENETICS APPLIED TO LIVESTOCK PRODUCTION, 8., 2006, Belo Horizonte. Proceeding. Belo Horizonte: Instituto Prociência, 2006. 1CD-ROM.

LIMA, F.P.; BONILHA NETO, L.M.; RAZOOK, A.G.; PACOLA, L.J.; FIGUEIREDO, L.A. de; PEIXOTO, A.M. Parâmetros genéticos em características morfológicas de bovinos Nelore. Boletim da Indústria Animal, v.46, p.249-257, 1989.

MELIS, M.H. van; ELER, J.P.; SILVA, J.A. de V.; FERRAZ, J.B.S. Estimação de parâmetros genéticos em bovinos de corte utilizando os métodos de máxima verossimilhança restrita e Â. Revista Brasileira de Zootecnia, v.32, p.1624-1632, 2003.

MISZTAL, I. REMLF90 manual. 2002. Disponível em: $<$ http://nce. ads.uga.edu/ ignacy/newprograms.html $>$. Acesso em: 6 abr. 2007.

MOSER, D.W.; BERTRAND, J.K.; MISZTAL, I.; KRIESE, L.A.; BENYSHEK, L.L.; Genetic parameters estimates for carcass and yearling ultrasound measurements in Brangus cattle. Journal of Animal Science, v.76, p.2542-2548, 1998.

REVERTER, A.; JOHNSTON, D.J.; GRASER, H.U.; WOLCOTT, M.L.; UPTON, W.H. Genetic analyses of live animal ultrasound and abattoir carcass traits in Australian Angus and Hereford cattle. Journal of Animal Science, v.78, p.1786-1795, 2000.

ROBINSON, D.L.; HAMMOND, K.; McDONALD, C.A. Live animal measurement of carcass traits: estimation of genetic parameters for beef cattle. Journal of Animal Science, v.71, p.1128-1135, 1993.

SAS INSTITUTE. SAS/STAT software: changes and enhancement through release 8.2. Cary: SAS Institute, 2000.

SHEPARD, H.H.; GREEN, R.D.; GOLDEN, B.L.; HAMLIN, K.E.; PERKINS, T.L.; DILES, J.B. Genetic parameter estimates of live animal ultrasonic measures of retail yield indicators in yearling breeding cattle. Journal of Animal Science, v.74, p.761-768, 1996.

STELZLENI, A.M.; PERKINS, T.L.; BROWN JUNIOR, A.H.; POHLMAN, F.W.; JOHNSON, Z.B.; SANDELIN, B.A. Genetic parameter estimates of yearling live animal ultrasonic measurements in Brangus cattle. Journal of Animal Science, v.80, p.3150-3153, 2002.

YOKOO, M.J.; ALBUQUERQUE, L.G.; LOBO, R.B.; BEZERRA, L.A.F.; ARAUJO, F.R.C.; SILVA, J.A.V.; SAINZ, R.D. Genetic and environmental factors affecting ultrasound measures of longissimus muscle area and backfat thickness in Nelore cattle.

Livestock Science, v.117, p.147-154, 2008.

Recebido em 14 de outubro de 2008 e aprovado em 30 de dezembro de 2008 